\title{
Refractive and Corneal Astigmatism in White School Children in Northern Ireland
}

\author{
Lisa O'Donoghue, ${ }^{1}$ Alicja R. Rudnicka, ${ }^{2}$ Julie F. McClelland, ${ }^{1}$ Nicola S. Logan, ${ }^{3}$ \\ Christopher G. Owen, ${ }^{3}$ and Kathryn J. Saunders ${ }^{1}$
}

Purpose. To study the prevalence of and relation between refractive and corneal astigmatism in white school children in Northern Ireland and to describe the association between refractive astigmatism and refractive error.

Methods. Stratified random clustering was used to recruit 1053 white children, 392 aged $6-7$ years and 661 aged $12-13$ years. Eye examinations included cycloplegic autorefraction and ocular biometric measures of axial length and corneal curvature.

Results. The prevalence of refractive astigmatism ( $\geq 1$ DC) did not differ significantly between 6- to 7-year-old children (24\%; $95 \%$ confidence interval [CI], 19-30) and 12- to 13-year-old children $(20 \% ; 95 \%$ CI, 14-25). The prevalence of corneal astigmatism ( $\geq 1$ DC) also did not differ significantly between 6- to 7-year-old children (29\%; 95\% CI, 24-34) and 12- to 13-year-old children (25\%; 95\% CI, 21-28). While levels of refractive astigmatism and corneal astigmatism were similar, refractive astigmatism was predominantly oblique (76\%; $95 \%$ CI, 67-85, of 6- to 7-year-olds; $59 \%$; $95 \%$ CI, $48-70$, of $12-$ to 13-year-olds), but corneal astigmatism was predominantly withthe-rule (80\%; 95\% CI, 72-87, of 6- to 7-year-olds; $82 \%$; $95 \% \mathrm{CI}$, $74-90$, of 12 - to 13-year-olds). The prevalence of refractive astigmatism was associated with increasing myopia and hyperopia.

Conclusions. This study is the first to provide robust population-based data on the prevalence of astigmatism in white school children in the United Kingdom. The prevalence of refractive astigmatism and corneal astigmatism is stable between 6 and 7 years and 12 and 13 years, although this finding would need to be confirmed by prospective studies. There is a high prevalence of refractive and corneal astigmatism which is associated with ametropia. (Invest Ophthalmol Vis Sci. 2011; 52:4048 - 4053) DOI:10.1167/iovs.10-6100

stigmatism is a clinically important condition ${ }^{1}$ : it is associ-
ated with reduced visual acuity ${ }^{2}$ and an increased risk of
treatment may be influenced by the orientation of the axis of
astigmatism. ${ }^{5}$ Two components of astigmatism can currently
be independently measured: refractive astigmatism and corneal

From the ${ }^{1}$ School of Biomedical Sciences, University of Ulster, Coleraine, Northern Ireland, United Kingdom; ${ }^{2}$ St. George's, University of London, London, United Kingdom; and ${ }^{3}$ Aston University, Ophthalmic Research Group, Aston University, Birmingham, United Kingdom

Supported by College of Optometrists, London, United Kingdom.

Submitted for publication June 22, 2010; revised October 21 and December 21, 2010, and February 16, 2011; accepted February 23, 2011.

Disclosure: L. O'Donoghue, None; A.R. Rudnicka, None; J.F. McClelland, None; N.S. Logan, None; C.G. Owen, None; K.J. Saunders, None

Corresponding author: Lisa O'Donoghue, Cromore Road, Coleraine, BT52 1SA, Northern Ireland, UK; 1.odonoghue@ulster.ac.uk. astigmatism, with the difference between these being due to internal astigmatism. Due to the effect of internal astigmatism, the magnitude of corneal astigmatism is generally greater than that of refractive astigmatism. ${ }^{6,7}$

Although there have been numerous reports on the prevalence of refractive astigmatism in school children, studies on populations of children with European ancestry have given divergent data with a prevalence of $26 \%{ }^{8}$ in the United States compared with $6.7 \%$ in Australia ${ }^{9}$ and $5.2 \%$ in Sweden, ${ }^{10}$ and few studies are available on the prevalence and distribution of either refractive or corneal astigmatism in UK or Irish school children.

As the population of Northern Ireland is ethnically homogenous (99\% white), ${ }^{11}$ the purpose of the present study is to describe the prevalence of refractive astigmatism in white school children, facilitating comparisons with other population-based surveys examining school-age children of predominantly European origin in Europe, Australia, and the United States. The association between the spherical component of the refraction and presence of refractive astigmatism is also described, together with the relationship between refractive and corneal astigmatism.

\section{Methods}

\section{Subjects}

The Northern Ireland Childhood Errors of Refraction (NICER) study is a population-based survey of school children aged 6-7 years and 12-13 years living in Northern Ireland. It is a sister study of the Aston Eye Study examining refractive error in a multiethnic urban population (Logan NS. IOVS 2008;49:ARVO E-Abstract 2602). The study was approved by the University of Ulster Research Ethics Committee, and the conduct of the study adhered to the tenets of the Declaration of Helsinki. After an explanation of the nature and possible consequences of the study, written consent was obtained from the parents or guardian of all children before the examination. The 12- to 13-year-old children also gave written consent, and verbal assent was obtained from the 6- to 7-year-old children.

The study methods have previously been described in detail. ${ }^{12}$ In brief, stratified random sampling of schools from geographic areas characteristic of Northern Ireland was used to obtain a representative sample of schools and children from urban/rural and deprived/nondeprived areas. Within individual schools, all children in one or more classes were invited to participate. In line with the Sydney Myopia Study (SMS), ${ }^{13}$ the protocol for data collection included cycloplegic autorefraction ( $1 \%$ cyclopentolate hydrochloride, Minims single dose; Chauvin Pharmaceuticals, Romford, UK) using a binocular open-field autorefractor (SRW-5000; Shin-Nippon, Tokyo, Japan). At least five measurements were taken with the representative value as determined by the instrument used in subsequent analyses. This autorefractor permits reliable measures of both the spherical and cylindrical $( \pm 0.24$ D SD) components of refraction. ${ }^{14}$ The ocular biometer (Zeiss IOLMaster; Carl Zeiss Meditec, Oberkochen, Germany) was used to take at 
least three measures of axial length and corneal curvature and five simultaneous measures of anterior chamber depth. The 95\% limits of agreement of the ocular biometer are $\pm 0.04 \mathrm{~mm}$ for mean corneal curvature measures, ${ }^{15}$ (which approximates to $\pm 0.22 \mathrm{D}$ ). Participants were tested within school premises during the school day, between May 2006 and March 2008.

\section{Data Analysis and Definitions}

Refractive astigmatism has been taken from the autorefractor result (absolute cylindrical value), and corneal astigmatism is defined as the difference between the flattest and steepest corneal meridians with the cylindrical axis set along the flattest meridian. The prevalence of astigmatism of $\geq 1.00, \geq 1.50$, and $\geq 2.00$ DC is reported.

The spherical value of the autorefractor result (written in negative cylindrical form) has been used to present data on the variation of the presence of refractive astigmatism of at least $1.00 \mathrm{DC}$ with refractive error. To classify astigmatism, with-the-rule (WTR) astigmatism is defined as a negative cylinder axes from $1^{\circ}$ to $15^{\circ}$ and from $165^{\circ}$ to $180^{\circ}$, against-the-rule (ATR) astigmatism as a negative cylinder axes between $75^{\circ}$ and $105^{\circ}$ and oblique astigmatism as axes from $16^{\circ}$ to $74^{\circ}$ or from $106^{\circ}$ to $164^{\circ}$. Although these definitions were chosen to facilitate comparisons with other studies, ${ }^{3,9}$ there is widespread variation in the classification of WTR, ATR, and oblique astigmatism across previous studies. $^{16}$

As refractive and corneal astigmatism are correlated between the right and left eyes (Spearman correlation refractive astigmatism 0.36 , corneal astigmatism 0.60 ; both $P<0.001$ ) only data from the right eye are presented. To fully describe the relationship between refractive and corneal astigmatism the cylinders and their axes were converted into vectors. ${ }^{17}$ A positive $J_{0}$ indicates WTR astigmatism and a negative $J_{0}$ indicates ATR astigmatism. A positive $J_{45}$ indicates the power is greatest at $135^{\circ}$, and a negative $J_{45}$ indicates that power is greatest at $45^{\circ}$. Spherical equivalent refraction (SER) is defined as the sphere $+1 / 2$ cylinder.

\section{Statistical Analysis}

All statistical analyses were carried out using commercially available software (Intercooled Stata 9.2; StataCorp, College Station, TX). As the distributions of refractive and corneal astigmatism are skewed toward lower levels of astigmatism, the median, interquartile ranges (IQR) and Spearman correlations have been used. Mann-Whitney $U$ test (equivalent to the Wilcoxon rank sum test) was used to compare median levels of astigmatism by age. Prevalence estimates with 95\% confidence intervals allowing for clustering of children within schools are presented. Here $\chi^{2}$ tests have been used to investigate age-group differences in both the prevalence of astigmatism (using three cutoffs: at least $1 \mathrm{DC}$, at least $1.5 \mathrm{DC}$, or at least 2DC) and prevalence of axes classification of astigmatism (WTR, ATR, or oblique). Kruskall-Wallis one-way analysis of variance was used to examine whether the median level of the spherical component of refraction and SER varied according to the axes classification of astigmatism. Results are considered statistically significant if $P<0.05$.

\section{Results}

\section{Participants}

Of the children invited to participate in the study, parental consent was obtained from $65 \%$ of 12 - to 13 -year-olds and $62 \%$ of 6- to 7-year-olds. Reflective of the Northern Irish population, $98.7 \%$ of participants were white, and this report presents data from 661 white children aged 12-13 years (50.5\% male) and 392 white children aged 6-7 years ( $49.5 \%$ male). The mean ages of the two study groups were 13.1 years (range, 12.114.1) and 7.1 years (range, 6.3-7.8), respectively.

\section{The Distribution and Prevalence of Refractive and Corneal Astigmatism}

The prevalence of refractive astigmatism ( $\geq 1$ DC) was $24 \%$ (95\% CI, 19-30) in 6- to 7-year-old children and 20\% (95\% CI, $14-25$ ) in 12- to 13-year-old children (Fig. 1). The prevalence of corneal astigmatism ( $\geq 1 \mathrm{DC}$ ) was $29 \%(95 \% \mathrm{CI}, 24-34)$ in 6- to 7-year-old children and $25 \%$ (95\% CI, 21-28) in 12- to 13-yearold children (Fig. 1). There are no statistically significant differences in the prevalence ( $\geq 1 \mathrm{DC}, \chi^{2}=3.13$ ) or median level $(z=1.8)$ of refractive astigmatism between the 6- to 7-year-old children (median $0.50 \mathrm{DC}, \mathrm{IQR} 0.25$ ) and the 12 - to 13 -year-old children (median 0.50 DC, IQR 0.50 ) or in the prevalence $(\geq 1$ DC, $\left.\chi^{2}=2.4\right)$ or median level $(z=1.9)$ of corneal astigmatism (6- to 7-year-old children, median 0.73 DC, IQR 0.55 ; 12 - to 13-year-old children, median 0.58 DC, IQR 0.70).

\section{The Distribution of the Axes of Refractive and Corneal Astigmatism}

There was no statistically significant age group difference in the prevalence of WTR, ATR, or oblique refractive or corneal astigmatism (all $\chi^{2}>0.1$ ). Although most refractive astigma-
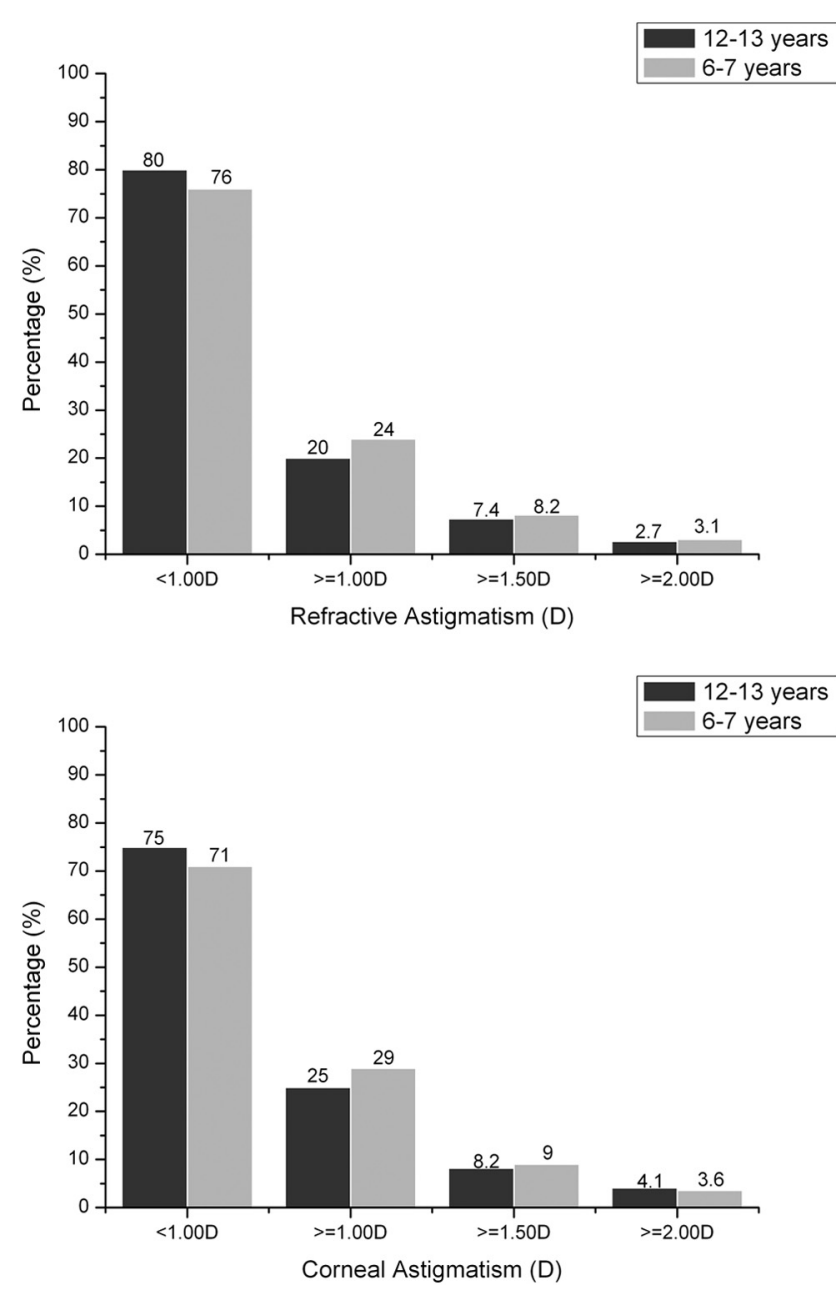

Figure 1. Prevalence of refractive and corneal astigmatism. Refractive astigmatism assessed using cycloplegic autorefraction; corneal astigmatism assessed using ocular biometer corneal curvature measures. Here 6- to 7-year-old children, $n=392 ; 12$ - to 13 -year-old children, $n=661$. For all three levels of astigmatism, there were no statistically significant age group differences in the prevalence of refractive (all $\chi^{2}>0.1$ ) or corneal astigmatism (all $\chi^{2}>0.1$ ). 


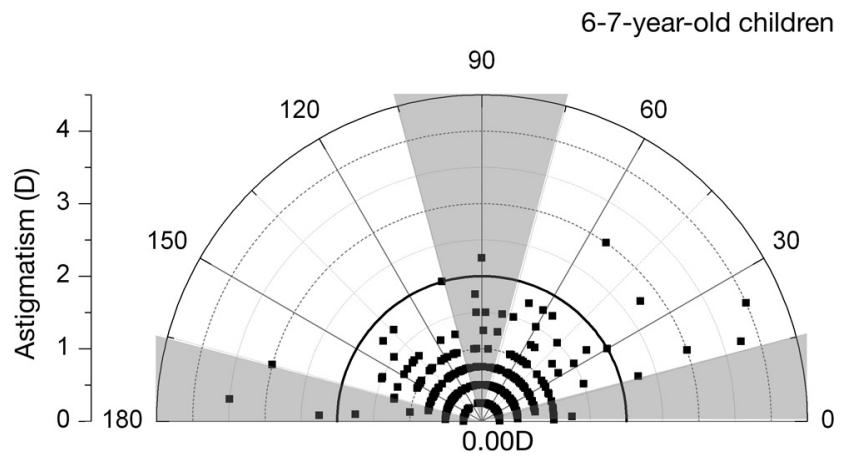

12-13-year-old children

90

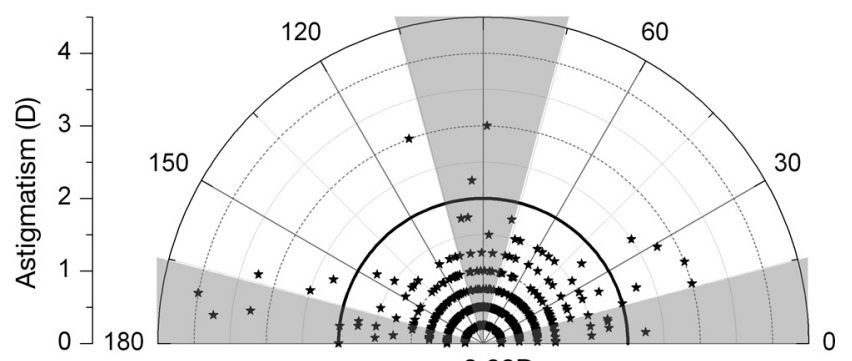

$0.00 \mathrm{D}$

FIGURE 2. Polar plots of refractive astigmatism. Refractive astigmatism assessed using cycloplegic autorefraction. 6- to 7-year-old children, $n=$ 392; 12- to 13-year-old children, $n=661$. D, diopters. The rings represent the magnitude of the astigmatism: the innermost point is 0 DC, with a step size between rings of $0.50 \mathrm{DC}$. The solid black line indicates $2 \mathrm{DC}$. The angles range from $0^{\circ}$ to $180^{\circ}$ and correspond to the range of angles for astigmatism. ${ }^{18}$ The shaded areas show WTR and ATR astigmatism. Here $8.4 \%(n=33)$ of 6 - to 7 -year-olds and $10.3 \%$ $(n=68)$ of 12 - to 13 -year-olds have refractive astigmatism $<0.25 \mathrm{DC}$.

tism ( $\geq 1.00$ DC) was classified as oblique (6- to 7-year-old children, $76 \% \mathrm{CI}, 67-85$; 12 - to 13 -year-old children, $59 \% \mathrm{CI}$, $48-70$ ), most corneal astigmatism ( $\geq 1.00$ DC) was WTR (6- to 7-year-old children, $80 \% \mathrm{CI}, 72-87$; 12 - to 13 -year-old children, $82 \%$ CI, 74-90). However, as this classification of astigmatism into WTR, ATR, and oblique is rather arbitrary, polar plots have been used to better illustrate the distribution of the axes of both refractive and corneal astigmatism. Polar plots also display the relationship between the magnitude and the axis of astigmatism. Figure 2 illustrates that most refractive astigmatism is $<2.00 \mathrm{DC}$ and shows the even distribution of the axes of RA. Figure 3 shows that most corneal astigmatism is also $<2 \mathrm{D}$.

\section{The Relationship between Refractive Astigmatism and Refractive Error}

There is a statistically significant association between greater amount of refractive astigmatism and the absolute value of spherical refraction (Spearman correlation: 6- to 7-year-old children, 0.23 ; 12 - to 13 -year-old children, 0.32 ). Figure 4 illustrates that the presence of refractive astigmatism of at least $1 \mathrm{D}$ increases with spherical error (both myopia and hyperopia) in 12- to 13-year-old children and with hyperopia in 6- to 7-yearold children. There is a low prevalence of myopia (of at least $-0.50 \mathrm{DS}$ SER) in 6- to 7-year-old children (2.0\% CI, 0.4-3.6) compared with 12- to 13 -year-old children (15.0\% CI, $10.7-$ 19.3).

There is no statistically significant difference in the median level of the spherical component of refraction or SER by axis classification (WTR, ATR, or oblique) in 6- to 7-year-old or 12to 13-year-old children (all Kruskall-Wallis $>0.2$ ).

\section{The Relationship between Corneal and Refractive Astigmatism}

Figure 5 illustrates the association between corneal and refractive $J_{0}$ and $J_{45}$ astigmatism in 12- to 13 -year-old children. Although corneal and refractive measures of $J_{45}$ (oblique) astigmatism are similar, the magnitude of refractive $J_{0}$ (regular) astigmatism is lower than corneal $J_{0}$. Similar associations were found in the 6- to 7-year-old age group (graphs not shown).

\section{Discussion}

\section{Refractive Astigmatism}

This is the first study to describe the prevalence of refractive astigmatism and its relationship with refractive error in a UK population. Although refractive astigmatism has been shown to change considerably throughout infancy, ${ }^{19,20}$ our data support previous reports (both cross-sectional and longitudinal) ${ }^{8,9,16,21}$ from other countries showing that refractive astigmatism is relatively stable throughout later childhood (5-15 years approximately). However, other studies have reported that the prevalence of refractive astigmatism increases ${ }^{22-24}$ or decreases $^{25}$ with age. The type of astigmatism may determine how it changes with age with reports of myopic astigmatism increasing and hyperopic astigmatism decreasing with age ${ }^{26,27}$ and increases in the prevalence of lower amounts of astigmatism ( $\geq 0.75$ DC) but not higher amounts of astigmatism ( $\geq 2.00$ DC) throughout childhood. ${ }^{22,24}$

\section{6-7-year-old children}

90

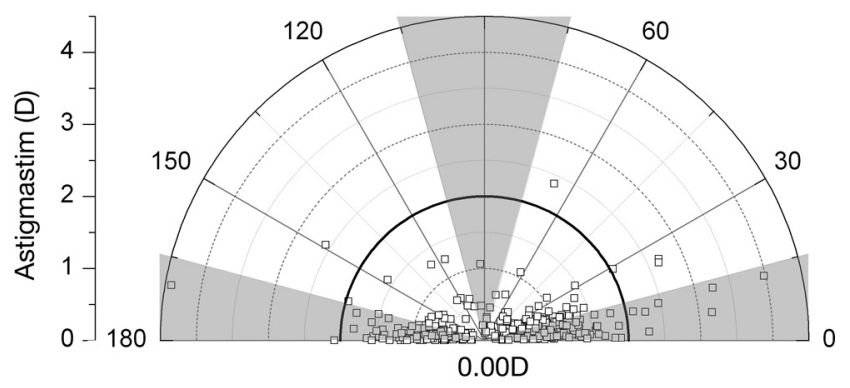

12-13-year-old children

90

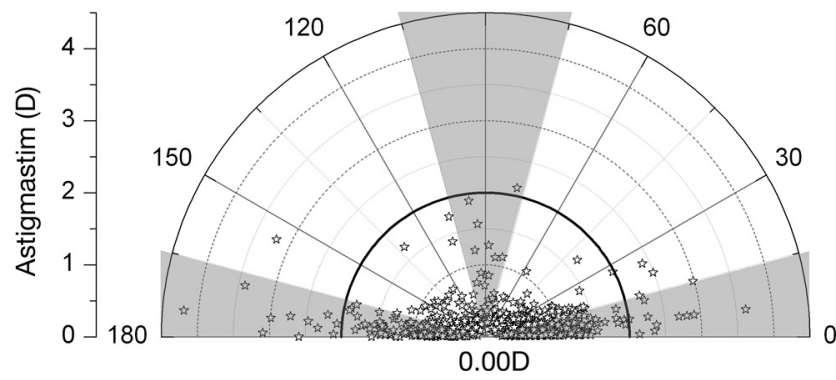

FIGURE 3. Polar plots of corneal astigmatism. Corneal astigmatism assessed using the ocular biometer. Here 6-to 7-year-old children, $n=$ 392 ; 12 - to 13-year-old children, $n=661$. D, diopters. The rings represent the magnitude of the astigmatism: The innermost point is 0 DC, with a step size between rings of $0.50 \mathrm{DC}$. The solid black line indicates $2 \mathrm{DC}$. The angles range from $0^{\circ}$ to $180^{\circ}$ and correspond to the range of angles for astigmatism. ${ }^{18}$ The shaded areas show WTR and ATR astigmatism. Here $6.6 \%(n=26)$ of 6 - to 7 -year-olds and $10.6 \%$ $(n=70)$ have corneal astigmatism $<0.25 \mathrm{DC}$. 
FiguRe 4. Distribution of refractive astigmatism of at least $1 \mathrm{D}$ by classification of spherical error. 6- to 7-year-old children, $n=392 ; 12$ - to 13-year-old children, $n=661$. Spherical error assessed by cycloplegic autorefraction, with the result recorded in minus cylindrical form.

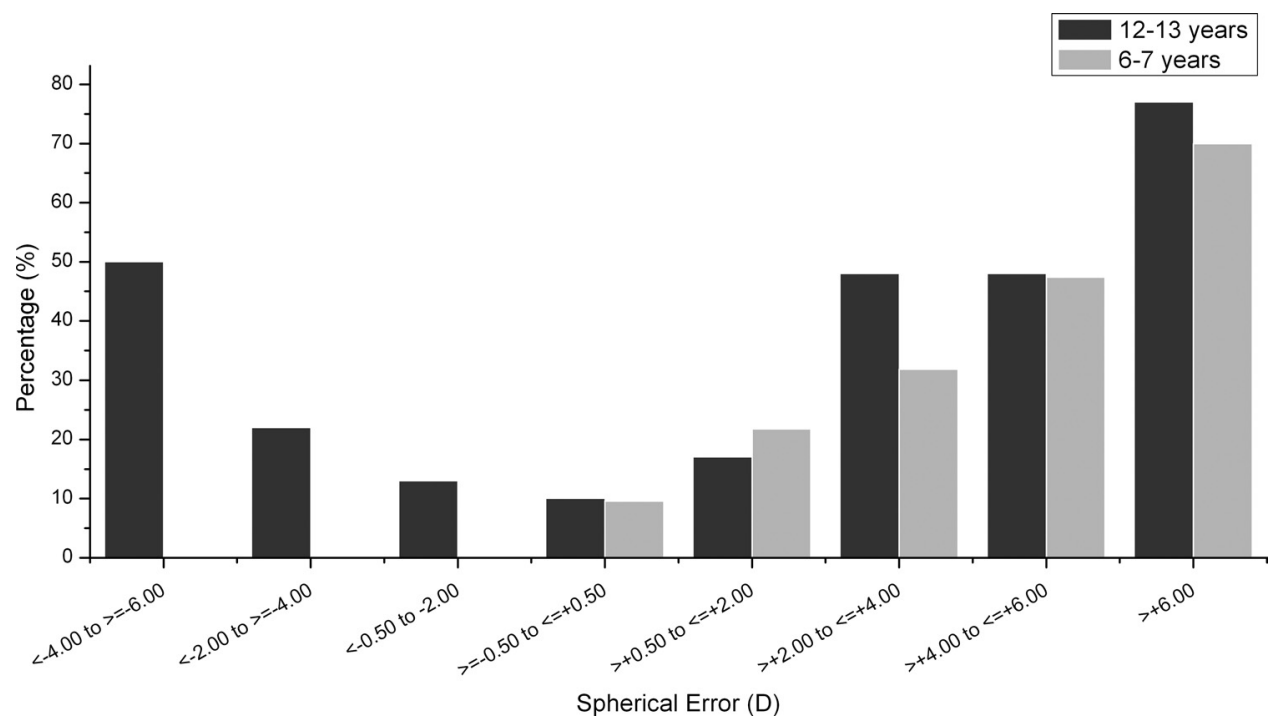

The prevalence of refractive astigmatism $\geq 1.00 \mathrm{DC}$ in the present study (6- to 7-year-olds, $24 \% 95 \% \mathrm{CI}, 18-30 ; 12$ - to 13-year-olds, $20 \% 95 \%$ CI 14-25) is much higher than that reported by the SMS in a largely white Australian population
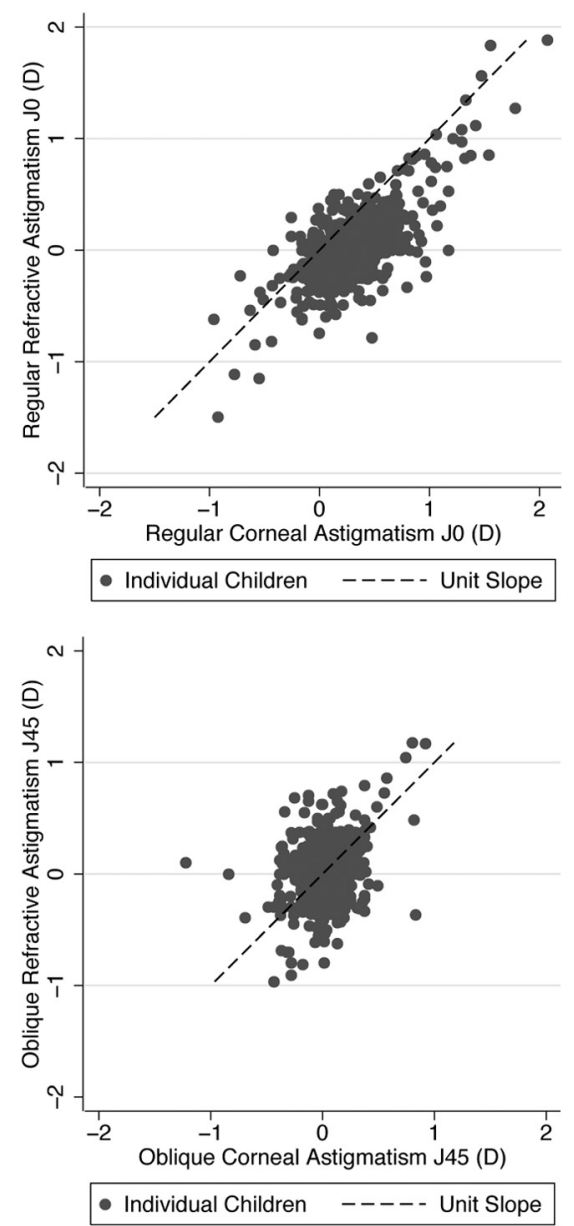

FIGURE 5. Relationship between corneal and refractive $J_{0}$ and $J_{45}$ values (12- to 13-year-old children). Twelve- to 13-year-old children, $n=661$. $J_{0}$, regular astigmatism; $J_{45}$, oblique astigmatism. Corneal astigmatism assessed with the ocular biometer; refractive astigmatism assessed with cycloplegic autorefraction. (12-year-olds, 6.7\%; 6-year olds, 4.8\%). ${ }^{9}$ However, the prevalence of refractive astigmatism in the UK NICER study is considerably lower when higher levels of astigmatism are considered (Fig. 1). The difference in the prevalence of refractive astigmatism between white school children in Australia in the SMS and those in the UK NICER study appears to be largely due to an increased prevalence of astigmatism of at least $1 \mathrm{D}$ but less than $2 \mathrm{D}$. These differences in the prevalence of refractive astigmatism may be associated with the different prevalence of ametropia in the two countries. In the UK NICER study the prevalence of ametropia (both myopia and moderate hyperopia) in 12- to 13-year-old children is of the order of three times greater than that reported for white children in Australia in the SMS. $^{28}$

The prevalence of refractive astigmatism in the present study is more in line with the $26 \%$ prevalence of at least 1.00 DC reported in white children (age 5 to 17 years) in the United States, ${ }^{8}$ where the prevalence of refractive astigmatism was also considerably lower (13.1\%) when the definition was amended to at least 1.25 DC. Other European data from Sweden $^{10}$ and Poland ${ }^{29}$ demonstrate lower prevalence rates compared with the United States or the UK NICER study. However both the Swedish and Polish studies used retinoscopic rather than autorefractor measures, and in many studies that have reported astigmatism using both techniques the prevalence of astigmatism is higher where autorefraction has been used. ${ }^{23-25,30}$

The widely reported differences in the prevalence of refractive astigmatism in white populations may reflect either genetic differences among white populations in different geographical locations or variations in environmental influences.

\section{The Distribution of the Axes of Refractive Astigmatism}

In the present study, across both age groups, most refractive astigmatism is classified as oblique, replicating the findings in Australian school children in the SMS. In contrast some studies using retinoscopy have reported that most refractive astigmatism in children aged 6 years is WTR. ${ }^{21,31,32}$

Both the current NICER study and the Australian SMS ${ }^{9}$ have used a broad definition of oblique astigmatism. Cowen and Bobier $^{33}$ classified astigmatism as oblique in $15 \%$ of preschool Canadian children using a definition of oblique astigmatism as $31^{\circ}-60^{\circ}$ and $121^{\circ}-150^{\circ}$, considerably narrower than the definition used in the present study. Using this definition the 
prevalence of oblique astigmatism in the present study reduces from $76 \%$ to $43 \%$ in 6 - to 7 -year-olds with astigmatism ( $\leq 1 \mathrm{DC}$ ) and from $59 \%$ to $23 \%$ of astigmatic 12 - to 13 -year-olds. Abrahamsson and Sjostrand ${ }^{34}$ have suggested that the presence of oblique astigmatism is subject to substantial geographical variations and have described oblique astigmatism as especially amblyogenic. However, the polar plots of the present study's data suggest that the axes of refractive astigmatism are evenly distributed, with the axes of higher levels of astigmatism closer to the horizontal and vertical axes rather than oblique, therefore possibly reducing the risk of astigmatic amblyopia.

\section{Refractive Astigmatism and Refractive Error}

Although it has been previously reported that hyperopic eyes are more likely to be astigmatic than myopic eyes ${ }^{35-37}$ and other studies have described an association between refractive astigmatism and myopia, ${ }^{19,38}$ the present study reports that the prevalence of refractive astigmatism in 12- to 13-year-old children increases with both increasing myopia and hyperopia. This association between ametropia and astigmatism supports that astigmatic blur in early life may impact on emmetropization, ${ }^{37}$ and studies describing the relation between refractive astigmatism and refractive error need to consider the prevalence of myopia and hyperopia in the population.

Although astigmatic refractive error does not differ between the two age groups, this does not preclude changes in astigmatic errors of individuals during childhood. Prospective studies are required to further evaluate the relationship between refractive astigmatism and refractive error development and environmental versus genetic influences.

\section{Corneal Astigmatism and Its Relation with Refractive Astigmatism}

The prevalence of corneal astigmatism $(\geq 1.00 \mathrm{DC})$ in the UK NICER study (6- to 7-year-olds, 29\%; 12- to 13 -year-olds, $25 \%$ ) is also higher than that reported in white Australian children by the SMS $^{9}$ (6- to 7 -year-olds, $22 \%^{39}$; 12 - to 13 -year-olds, $19 \%$ ). The NICER study confirms previous reports that corneal astigmatism exceeds refractive astigmatism, ${ }^{9,39-41}$ and the higher levels of refractive astigmatism compared with Australian school children in the SMS appears to be due to the higher level of corneal astigmatism.

Future studies should try to establish if risk factors for astigmatism are genetic, environmental or a combination of both. Prospective studies from infancy would be of help in identifying whether factors contributing to astigmatism occur before the onset of ametropia or as a consequence of it.

\section{Limitations}

Due to ethical constraints, the authors were unable to determine reasons for nonparticipation in the study.

\section{Conclusions}

This is the first epidemiologic study to describe the prevalence of refractive and corneal astigmatism in a Northern Irish population: There is a high prevalence of both refractive and corneal astigmatism in white children in Northern Ireland, and refractive astigmatism is associated with both myopia and hyperopia. Both refractive and corneal astigmatism are relatively stable between the ages of 6-7 and 12-13 years. The high prevalence of refractive astigmatism has important implications for service planning due to the association between refractive astigmatism and amblyopia.

\section{References}

1. Read SA, Collins MJ, Carney LG. A review of astigmatism and its possible genesis. Clin Exp Optom. 2007;90:5-19.

2. Leone JF, Mitchell P, Morgan IG, et al. Use of visual acuity to screen for significant refractive errors in adolescents: is it reliable? Arch Opbthalmol. 2010;128:894-899.

3. Fan DS, Rao SK, Cheung EY, et al. Astigmatism in Chinese preschool children: prevalence, change, and effect on refractive development. Br J Opbthalmol. 2004;88:938-941.

4. Abrahamsson M, Fabian G, Sjostrand J. A longitudinal study of a population based sample of astigmatic children. II. The changeability of anisometropia. Acta Opbthalmol (Copenb). 1990;68: 435-440.

5. Somer D, Budak K, Demirci S, et al. Against-the-rule (ATR) astigmatism as a predicting factor for the outcome of amblyopia treatment. Am J Opbthalmol. 2002;133:741-745.

6. Grosvenor T, Quintero S, Perrigin DM. Predicting refractive astigmatism: a suggested simplification of Javal's rule. Am J Optom Pbysiol Opt. 1988;65:292-297.

7. Keller PR, Collins MJ, Carney LG, et al. The relation between corneal and total astigmatism. Optom Vis Sci. 1996;73:86-91.

8. Kleinstein RN, Jones LA, Hullett $\mathrm{S}$, et al. Refractive error and ethnicity in children. Arch Opbthalmol. 2003;121:1141-1147.

9. Huynh SC, Kifley A, Rose KA, et al. Astigmatism in 12-year-old Australian children: comparisons with a 6-year-old population. Invest Opbthalmol Vis Sci. 2007;48:73-82.

10. Villarreal MG, Ohlsson J, Abrahamsson M, et al. Myopisation: the refractive tendency in teenagers. prevalence of myopia among young teenagers in Sweden. Acta Opbthalmol Scand. 2000;78: 177-181.

11. Northern Ireland Statistics Research Agency (NISRA). Available at: www.nisra.gov.uk. Accessed June 22, 2006.

12. O'Donoghue L, Saunders KJ, McClelland JF, et al. Sampling and measurement methods for a study of childhood refractive error in a UK population. Br J Ophthalmol. 2010;94:1150-1154.

13. Ojaimi E, Rose KA, Smith W, et al. Methods for a population-based study of myopia and other eye conditions in school children: the Sydney Myopia Study. Opbthalmic Epidemiol. 2005;12:59-69.

14. Mallen EA, Wolffsohn JS, Gilmartin B, et al. Clinical evaluation of the Shin-Nippon SRW-5000 autorefractor in adults. Opbthalmic Physiol Opt. 2001;21:101-107.

15. Santodomingo-Rubido J, Mallen EA, Gilmartin B, et al. A new non-contact optical device for ocular biometry. Br J Ophthalmol. 2002;86:458-462.

16. Harvey EM, Dobson V, Miller JM. Prevalence of high astigmatism, eyeglass wear, and poor visual acuity among Native American grade school children. Optom Vis Sci. 2006;83:206-212.

17. Thibos LN, Wheeler W, Horner D. Power vectors: An application of Fourier analysis to the description and statistical analysis of refractive error. Optom Vis Sci. 1997;74:367-375.

18. Holladay JT, Dudeja DR, Koch DD. Evaluating and reporting astigmatism for individual and aggregate data.J Cataract Refract Surg. 1998;24:57-65.

19. Gwiazda J, Grice K, Held R, et al. Astigmatism and the development of myopia in children. Vision Res. 2000;40:1019-1026.

20. Mutti DO, Mitchell GL, Jones LA, et al. Refractive astigmatism and the toricity of ocular components in human infants. Optom Vis Sci. 2004;81:753-761.

21. Hirsch MJ. Changes in astigmatism during the first eight years of school-an interim report from the Ojai longitudinal study. Am J Optom Arch Am Acad Optom. 1963;40:127-132.

22. He M, Huang W, Zheng Y, et al. Refractive error and visual impairment in school children in rural Southern China. Opbthalmology. 2007; 114:374-382.

23. Naidoo KS, Raghunandan A, Mashige KP, et al. Refractive error and visual impairment in African children in South Africa. Invest Ophthalmol Vis Sci. 2003;44:3764-3770.

24. Dandona R, Dandona L, Srinivas M, et al. Refractive error in children in a rural population in India. Invest Opbthalmol Vis Sci. 2002;43:615-622. 
25. He M, Zeng J, Liu Y, et al. Refractive error and visual impairment in urban children in Southern China. Invest Opbthalmol Vis Sci. 2004;45:793-799.

26. Tong L, Saw SM, Lin Y, et al. Incidence and progression of astig matism in Singaporean children. Invest Ophthalmol Vis Sci. 2004 45:3914-3918.

27. Shih YF, Hsiao CK, Tung YL, et al. The prevalence of astigmatism in Taiwan schoolchildren. Optom Vis Sci. 2004;81:94-98.

28. O'Donoghue L, McClelland JF, Logan NS, et al. Refractive error and visual impairment in school children in Northern Ireland. $\mathrm{Br} J$ Opbthalmol. 2010;94:1155-1159.

29. Czepita D, Mojsa A, Ustianowska M, et al. Prevalence of refractive errors in schoolchildren ranging from 6 to 18 years of age. Ann Acad Med Stetin. 2007;53:53-56.

30. Goh PP, Abqariyah Y, Pokharel GP, Ellwein LB. Refractive error and visual impairment in school-age children in Gombak district, Malaysia. Ophthalmology. 2005;112:678-685.

31. Dobson V, Fulton AB, Sebris SL. Cycloplegic refractions of infants and young children: the axis of astigmatism. Invest Ophthalmol Vis Sci. 1984;25:83-87.

32. Gwiazda J, Scheiman M, Mohindra I, et al. Astigmatism in children: changes in axis and amount from birth to six years. Invest $O p b$ thalmol Vis Sci. 1984;25:88-92.
33. Cowen L, Bobier WR. The pattern of astigmatism in a Canadian preschool population. Invest Opbthalmol Vis Sci. 2003;44:45934600.

34. Abrahamsson M, Sjostrand J. Astigmatic axis and amblyopia in childhood. Acta Opbthalmol Scand. 2003;81:33-37.

35. Baldwin WR, Mills D. A longitudinal study of corneal astigmatism and total astigmatism. Am J Optom Pbysiol Opt. 1981;58:206-211.

36. Garber JM. The relation of astigmatism and hyperopia (more effective plus). J Am Optom Assoc. 1985;56:491-493.

37. Dobson V, Harvey EM, Miller JM. Spherical equivalent refractive error in preschool children from a population with a high prevalence of astigmatism. Optom Vis Sci. 2007;84:124-130.

38. Tong L, Saw SM, Carkeet A, et al. Prevalence rates and epidemiological risk factors for astigmatism in Singapore school children. Optom Vis Sci. 2002;79:606-613.

39. Huynh SC, Kifley A, Rose KA, et al. Astigmatism and its components in 6-year-old children. Invest Opbthalmol Vis Sci. 2006;47: 55-64.

40. Dobson V, Miller JM, Harvey EM. Corneal and refractive astigmatism in a sample of 3- to 5-year-old children with a high prevalence of astigmatism. Optom Vis Sci. 1999;76:855-860.

41. Grosvenor T, Ratnakaram R. Is the relation between keratometric astigmatism and refractive astigmatism linear? Optom Vis Sci. 1990;67:606-609. 